\title{
Advanced characterization techniques of the scour hole around a bridge pier model
}

\author{
Ana Margarida Bento $^{1, *}$, Lúcia Couto $^{2}$, João Pedro Pêgo ${ }^{1}$, and Teresa Viseu $^{2}$ \\ ${ }^{1}$ Faculdade de Engenharia da Universidade do Porto (FEUP), Rua Dr. Roberto Frias, s/n 4200-465, \\ Porto, Portugal \\ ${ }^{2}$ Laboratório Nacional de Engenharia Civil (LNEC), Avenida do Brasil, 101, 1700-066, Lisboa, \\ Portugal
}

\begin{abstract}
Local scouring around bridge foundations is a major reason for bridge collapse worldwide. It occurs due to the formation of vortices around bridge foundations as a result of changing the unidirectional approach flow into the three-dimensional field in an erodible channel bed, leading to the development of a scour hole in its vicinity. In the present work, two different techniques were applied for a full characterization of the scour hole geometry developed in a sand bed flume experiment by means of a Kinect sensor and a close-range photogrammetry. These advanced survey and sensor technologies offer efficient techniques of deriving point clouds and Digital Elevation Models (DEMs), respectively. The potential, limitations and results of both techniques are herein examined and conveniently compared, including a description of measurement devices, reference points and respective software. Reliable and accurate estimates of the topographic representation of the scour hole and inherent features were obtained. The design of the bridge pier used, with a $0.14 \mathrm{~m}$ wide rectangular round-nose concrete column (henceforth termed as oblong pier), replicates the typical shape used in the $19^{\text {th }}$ and $20^{\text {th }}$ centuries, and are the most common in Portugal.
\end{abstract}

\section{Introduction}

The collapse of bridges inevitably leads to economically losses and not seldom is responsible for human losses. Local scouring around the foundations is the most common bridge failure cause worldwide [1,2]. The presence of a bridge pier leads to the formation of a scour hole, from which entrainment and transport of sediments are influenced by the turbulent structures therein developed. Thus, once formed, such scour holes play a major role in the scouring process such as modifying the incoming flow patterns. The knowledge of the main scouring factors, their impact on the erosion process and their evolution in time is therefore essential for providing mechanisms and improved tools to minimise potential consequences as catastrophic failures, namely the inevitable and subsequent economical losses and human casualties. These serious threats have recently increased the awareness and interest in bridge scour research.

\footnotetext{
* Corresponding author: ana.bento@,fe.up.pt
} 
The complex flow-pier-sediment interaction phenomenon, underlying the local lowering of the streambed elevation at the bridge pier's vicinity, has justified the considerable amount of studies performed in the past decades. The mechanism of flow and scour development near a circular pier was initially described under specific conditions [3], while in other researches a variety of flow conditions, bridge foundations, and sediments features were considered (such as in [4] and the references therein), with the general purpose of better explaining the whole process. In spite of a notable number of scientific researches on scouring around bridge foundations, the relationships developed for the evaluation of the maximum scour depth and its temporal evolution $[1,5]$ are still lacking reliability. Further detailed investigations on the scour hole morphology are thus required for the development of a broader and comprehensive approach for predicting scour at bridge design phases. It is also worth highlighting that the numerical modelling of scouring, namely using Computational Fluid Dynamics (CFD) tools, is on the rise. Hence, a great demand arises for experimental approaches in order to improve the calibration and validation phases of the simulation models, which are currently used to complement laboratory-testing efforts [6].

Over decades, the most common approach for studying the scouring process was the point-wise measurements of the bed level at few locations. This has been performed either by using gauges and probe sensors $[7,8]$ or by employing scales that are being recorded with periscopes or cameras inside the transparent walls of the flume or of the pier model [9-11]. Other approaches involved the use of probes mounted on traversing mechanisms [12, 13]. Although capable of representing the bed surface, the intrusiveness of the technique may alter the approach flow field and consequently the scour hole features. Two and three-dimensional (2D and 3D) laser scanners have provided reliable results of the evolution of sandy beds for relatively calm free surfaces, which are difficult to guarantee in the vicinity of an hydraulic structure such as a bridge pier model. The recent advances in technology have been replacing the topographic information retrieved from traditional cross-section models by the threedimensional (3D) and point clouds and Digital Elevation Models (DEMs).

Several efforts have involved the application of close-range photogrammetry in local scouring experiments under well-controlled conditions; this technique was successfully applied in the reconstruction of the scour hole around a single and a complex bridge pier [14, 15]. The accuracy and the minimum of financial outlay are thus of primary importance when planning a survey of three-dimensional surface maps. Another valuable and attractive alternative to expensive 3D laser scanners is the Kinect sensor [16, 17]. The application of image-based techniques constitutes, thus, a suitable way to build the three-dimensional model of the developed scour hole around a bridge pier with high spatial resolution.

Therefore, the aim of the present work is to explore the two image-based techniques Kinect sensor and close-range photogrammetry - in a laboratory environment, for the characterization of the scour hole geometry caused by the presence of a bridge pier model in a movable bed. In the present study, an oblong pier is tested since it is the most common shape in Portuguese bridges, used in the $19^{\text {th }}$ and $20^{\text {th }}$ centuries.

Following this Introduction, Section 2 gives a brief description of the experimental setup, instrumentation and procedures. The two image processing techniques are also presented and their particularities explained. In Section 3, some phenomenological features of the resulting $3 \mathrm{D}$ scour hole are described and compared in order to highlight/outline the potential and limitations of the techniques herein applied. Finally, Section 4 presents the conclusions of this work. 


\section{Experimental Facilities and Methodologies}

\subsection{Experimental facility and conditions}

A local scouring experiment, reproducing the flow at the vicinity of a small-scale bridge pier embedded in a uniform sediment bed, was performed in a $40.7 \mathrm{~m}$ long, $2.0 \mathrm{~m}$ wide and $1.0 \mathrm{~m}$ deep glass-sided rectangular tilting flume (CIV) at the National Laboratory of Civil Engineering (LNEC), Lisbon, Portugal.

The working section consists of a sand recess box, $5.0 \mathrm{~m}$ long and $0.4 \mathrm{~m}$ deep, preceded by a metallic grid at the inlet of the flume, ensuring the development of a uniform approach flow distribution. A $0.3 \mathrm{~m}$ thick and $0.2 \mathrm{~m}$ long fine gravel mattress, embedded at the upstream end of the recess box and properly levelled by the adjacent concrete, allowed a smooth and progressive transition, avoiding scouring at the transition between the fixed and the movable bed.

The bridge pier model does not reproduce a specific bridge pier, but its design replicates the typical shape of bridge foundations most common in Portugal. The $0.14 \mathrm{~m}$ wide $(D)$ rectangular round-nose concrete column (hereinafter referred to as oblong pier) was installed in the middle of a recess box (Figure 1) filled with a uniform quartz sand, characterized by a mean sediment diameter $\left(D_{50}\right)$ of $0.86 \mathrm{~mm}$, a specific gravity $(s)$ of 2.65 , and a geometrical standard deviation $\left(\sigma_{D}\right)$ of 1.28 . The sediment coarseness ratio $\left(D / D_{50}\right)$ assumed the value of 163, not negligible according to recent studies [18]. The influence of flume sidewall on the scour hole development was avoided [19] in this case since the pier width was lower than $10 \%$ the flume width $(D / B=7 \%)$.

The inflow discharge $(Q)$ was regulated to the constant value of $0.120 \mathrm{~m}^{3} / \mathrm{s}$ by an electromagnetic flowmeter, positioned on the feeder pipe. Two sluice gates of the facility, one placed at upstream and other at downstream section, enabled the approach flow depth (h) adjustment inside the flume to $0.182 \mathrm{~m}$. The scour depth at the pier front was measured with a $\pm 0.1 \mathrm{~mm}$ accurate limnimeter. The flow was developed under a flow intensity close to unity, assuming a critical flow velocity of $u_{c}=0.319 \mathrm{~m} / \mathrm{s}$ [20]. The ratio of flume width to flow depth $(B / h)$ assumed the value of 11 , which allowed neglecting relevant wall effects on the flow field. A flow shallowness of 1.30 was used in the present experiment.
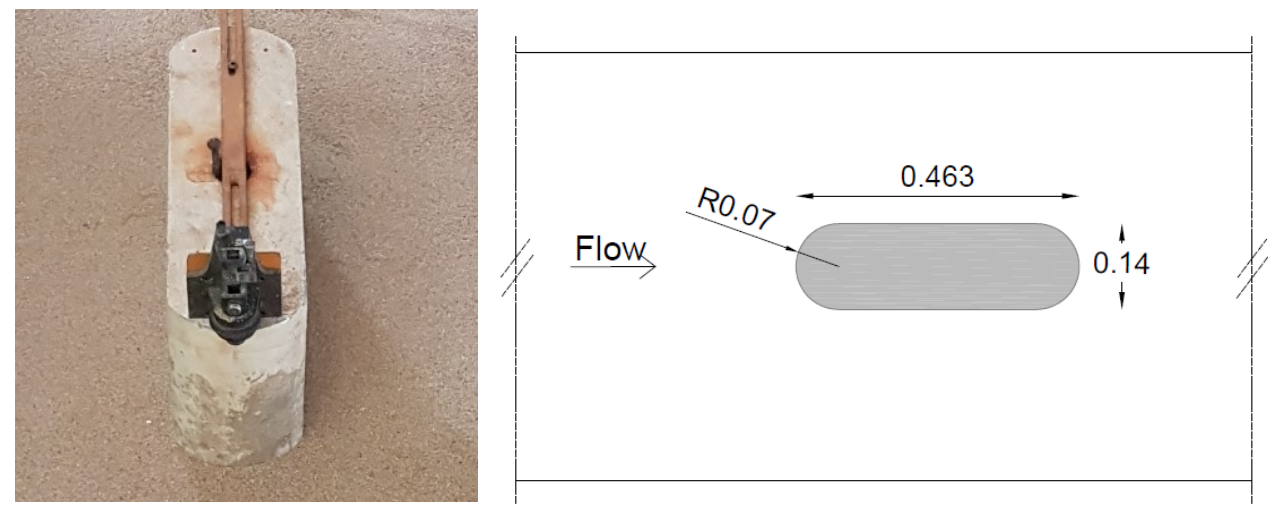

Fig. 1. Oblong bridge pier model (dimensions in meters).

\subsection{Procedure and methodology}

After the installation of the oblong pier, the recess box was filled with the sand, and flattened before the experiment began. In the area around the pier model, metallic plaques covering 
the sand were carefully removed only when the prescribed flow condition was reached, initiating, thus, the local scouring experiment.

This experiment ran for three days with the aim of characterizing the resulting scour hole geometry, through two different image-based techniques: Kinect sensor and close-range photogrammetry. Both approaches required the previous emptying of the tilting flume and control ground points, deployed in specific points of well-known dimensions on the model, for their suitable applications. In the following subsection, the main components, instruments and procedures followed by each application are addressed.

\subsection{Scour hole characterization}

\subsubsection{Kinect sensor}

The Microsoft Kinect technique consists of a projector and two internal cameras: one Infrared camera and a $R G B$ camera (Figure $2 \mathrm{a}$ ). The Infrared projector transmits a predefined pattern of light that is deformed based on the distance of various points of the object from the sensor. The deformed pattern is captured by the infrared camera and is correlated against a reference speckle pattern projected on the surface at known distance from the sensor to build a 3D map of the object.

The procedure of obtaining the scour hole surfaces includes the post-processing of the acquired images by using a software for $3 \mathrm{D}$ net processing (CloudCompare). The resulting point clouds are also used in the creation of topographic maps using mapping software of contours and 3D surfaces.

\subsubsection{Close-range photogrammetry}

The application of this technique required a digital camera and a set of ground control points. The camera was used to photograph the scour hole and the surrounding affected area, at different locations at a height $(H)$ of $0.50 \mathrm{~m}$ from the initial flatbed (Figure $2 \mathrm{~b}$ ). The ground control points, specific points in two lateral rulers, were used to accomplish the spatial reference of the model. Six ground control points were considered in this study.

The photogrammetric processing software used was Agisoft PhotoScan Professional. The digital elevation models $(D E M s)$ were then extracted and introduced in an post-processing software (Paraview) to enable the creation of bed contour surfaces and profiles.

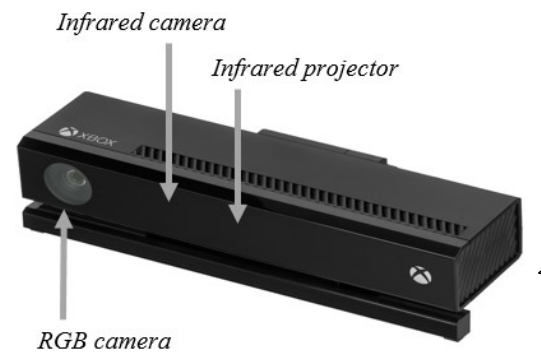

(a)

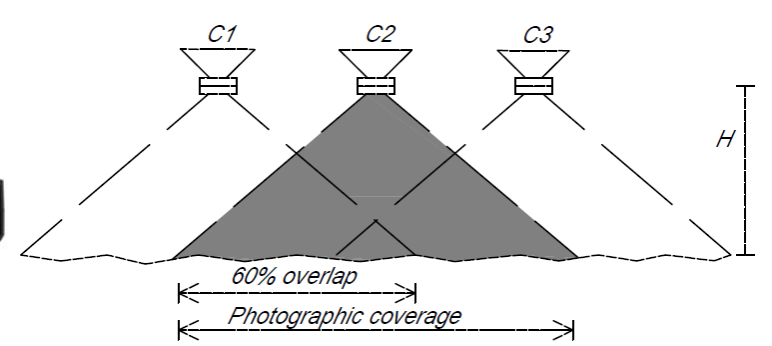

(b)

Fig. 2. Kinect sensor (a) and close-range photogrammetry scheme (b). 


\section{Results and comparative analysis of techniques}

\subsection{Scour hole}

The point clouds and the digital elevation models were produced and used to compute the contour lines and the 3D surfaces. Figure 3 plots the distribution of the local scour in the vicinity of the oblong pier as a function of bed scour depth-to-approach flow depth ratio $(d s / h)$. The 3D surface maps are presented in Figure 4.

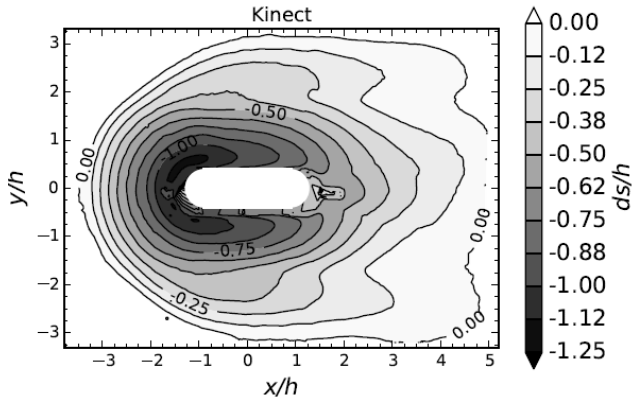

(a)

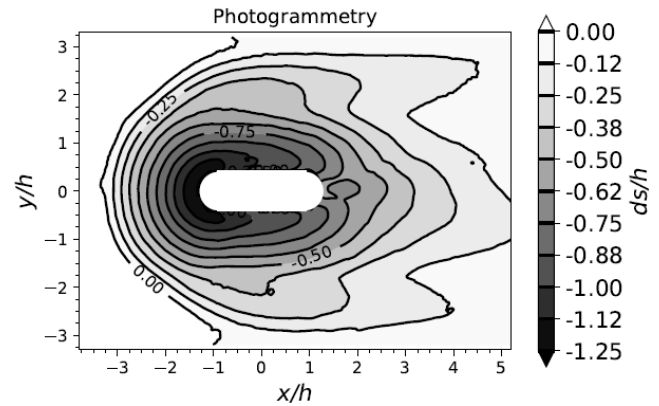

(b)

Fig. 3. Contours of local scour around the oblong pier from Kinect sensor (a) and close-range photogrammetry (b).

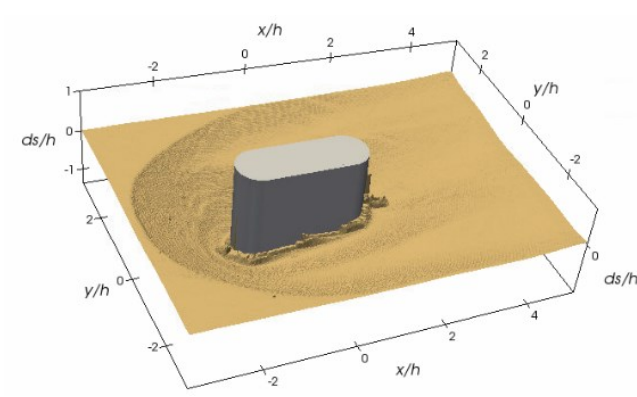

(a)

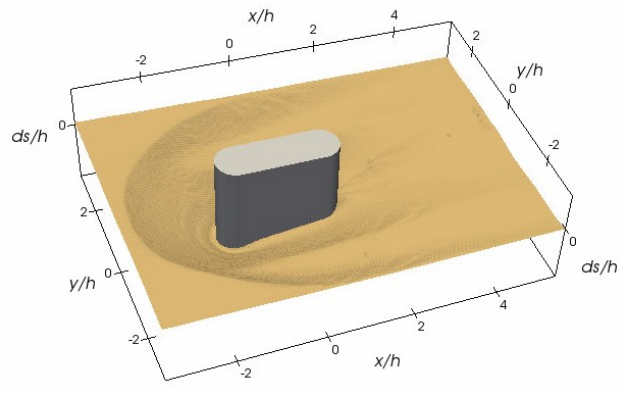

(b)

Fig. 4. Three-dimensional surface maps from Kinect sensor (a) and close-range photogrammetry (b).

The contours and the 3D surface maps represent data giving a valuable insight concerning the characterization of the scour hole geometry at the vicinity of the pier model under study. The results obtained by the different techniques are clearly similar as can be seen in Figures 3 and 4 , and will be better described on the following subsection.

\subsection{Scour bed profiles}

Figure 5 sketches the scour bed profiles considered in the present analysis. These profiles, normalized by the approach flow depth, are presented in Figure 6. A direct comparison between the aforementioned techniques can thus be performed. 


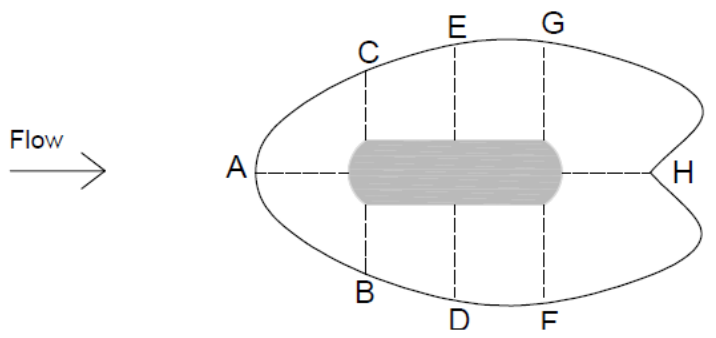

Fig. 5. Scheme of the scour bed profiles.
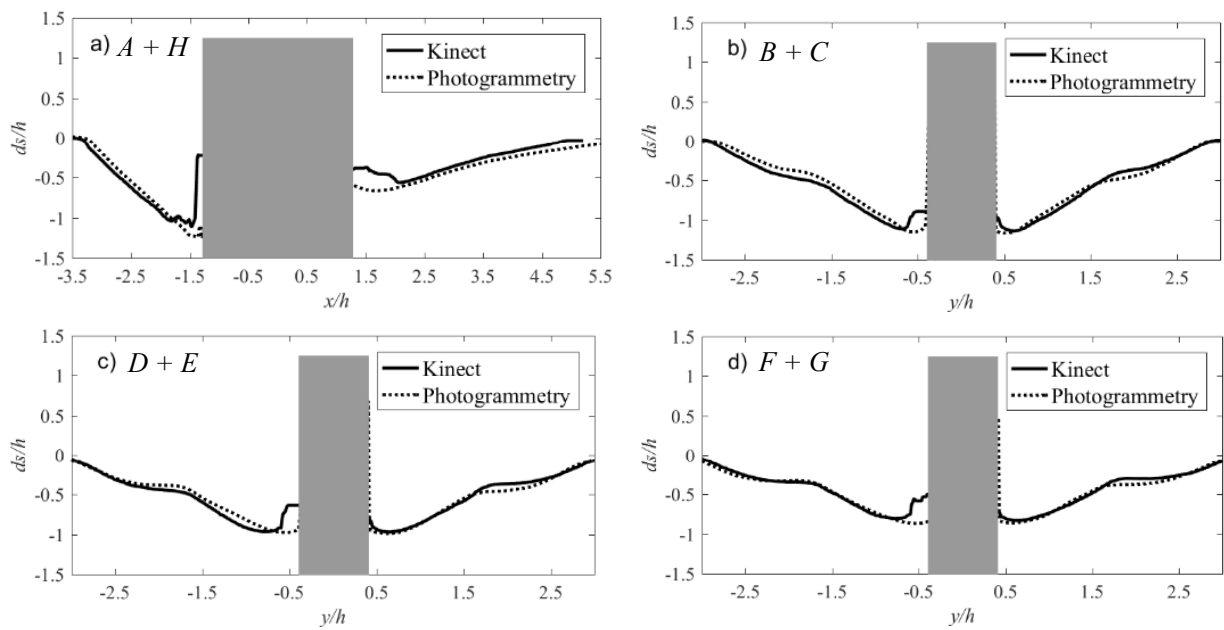

Fig. 6. Scour bed profiles normalized by the flow depth from Kinect sensor (continuous line) and closerange photogrammetry (dashed line): (a) $A+H$; (b) $B+C$; (c) $D+E$; and (d) $F+G$.

Figure 6 compares the scour depth profiles extracted from the Kinect sensor and the closerange photogrammetry at the vicinity of the oblong pier. Before analysing these profiles it should be mentioned that the structure at the top surface of the pier constituted an obstruction to the Kinect sensor, therefore the scour bed surface close to the pier wall could not be measured accurately, which justifies the erroneous results on that area. For this reason, the close-range photogrammetry results (dashed line) are herein compared with the Kinect's scour bed profiles (continuous line) measured at $0.03 \mathrm{~m}$ away from the pier round walls and left side (looking from upstream to downstream). Nevertheless, it can be stated that in general a good agreement was achieved.

The most affected profile in a scouring experiment is usually the longitudinal one, aligned with the approach flow direction, corresponding to profiles $A$ and $H$ in Figure 6a. Particular analysis is thus performed for these profiles. Very close descending slopes were registered for profile $A$ by both techniques; Kinect sensor gave a value of $66.4 \%$ while the application of close-range photogrammetry returned the value of $68.1 \%$. Even in profile $H$, on the deposition zone, the slopes were once again quite similar: $15.9 \%$ and $14.1 \%$, for the Kinect sensor and the photogrammetry techniques, respectively. As for maximum scour depth observed in profile $A$, it was obtained a value of $0.229 \mathrm{~m}$ with photogrammetry, corresponding to $1.26 \mathrm{~h}$ in Figure 6a. This value is corroborated by the $0.23 \mathrm{~m}$ observed on the limnimeter, placed at the pier front throughout the experiment. In the same way, from the analysis of the other profiles it may be concluded that both techniques were able to reconstruct the scour hole geometry with reliable detail and accuracy. 
Regarding some of the main features that can be relevant in the two image-based applied techniques, emphasis should be given to the number of photos/scans, the processing complexity, the precision/accuracy, and the light conditions dependency. Only one scan was used for the application of the Kinect sensor, while a set of 100 photographs were considered in the present analysis for the close-range photogrammetry. In terms of processing complexity, the photogrammetry application followed a step-by-step procedure towards the obtaining of the DEMs. After combining the depth information for each camera, the mesh model was built after being spatially referenced with the coordinated ground control points. On the other hand, the Kinect sensor provides the mesh of the model directly, just requiring the referencing task. The identification of the control points in the scan from the Kinect sensor required greater caution than for the photogrammetry case. Accuracies of $0.001 \mathrm{~m}$ and 0.0005 $\mathrm{m}$ were obtained from the application of the Kinect sensor and the close-range photogrammetry, respectively. Neither of the techniques unveiled much dependency on light specific conditions.

\section{Conclusions}

This paper presents an essay on the characterization of the scour hole around an oblong pier by using two distinct image-based technique approaches: a Kinect sensor and the application of close-range photogrammetry. Both techniques were applied on the scour hole developed during a 3-days test carried out in a $2 \mathrm{~m}$ wide flume, with the bottom covered by uniform sand and where an oblong pier with main dimensions of $0.14 \mathrm{~m}$ and $0.463 \mathrm{~m}$ was used.

Reliable and accurate estimates of the topographic representation of the scour hole and inherent features were herein obtained, presenting solely slight discrepancies (Figure 6). The analysis undertaken revealed that both are promising approaches in the research field of local scouring phenomena since they satisfy the required precision in accessible and effortless ways. These image-based techniques allowed important insights into the whole scour geometry around the bridge pier model under study.

In the authors' point of view, the obtained results from this study constitute a positive initial step towards the numerical modelling of scour hole dimensional features around bridge piers. This task may provide, once properly calibrated, a better and a valuable insight of scouring phenomena without the limitations of measurements and scale effects.

The Portuguese Foundation for Science and Technology (FCT) supported this research work, through the PhD scholarship PD/BD/127798/2016, in the framework of the Doctoral Program INFRARISK Analysis and Mitigation of Risks in Infrastructures.

\section{References}

1. B.W. Melville, S.E. Coleman, Bridge Scour. Water Resources Publications, LLC, Colorado, USA (2000)

2. W. Cook, P.J. Barr, M.W. Halling, Bridge failure rate. J. of Performance of Constructed Facilities, 29(3) (2013)

3. E.M. Laursen, A. Toch, Scour around bridge piers and abutments, 4, Iowa Highway Research Board, Ames, IA, USA (1956)

4. Y.W. Chang, G. Constantinescu, S. Miyawaki, W.F. Tsai, H.C. Lien, The flow and turbulence structure at a rectangular bridge pier with a low angle of attack. Proceedings of River Flow 2010, 681 - 689, Germany (2010) 
5. E.V. Richardson, S.R. Davis, Evaluating scour at bridges. $3^{\text {rd }}$ edition, FHWA IP 90017, Hydraulic Engineering Circular No. 18, National Highway Institute, U. S. Department of Transportation, Federal Highway Administration (1995)

6. R. Ettema, G. Constantinescu, B.W. Melville, Flow-Field Complexity and Design Estimation of Pier-Scour Depth: Sixty Years since Laursen and Toch, J. Hydraul. Eng., ASCE, 143(9) (2017)

7. G. Oliveto, W.H. Hager, Temporal evolution of clear-water pier and abutment scour, J. Hydraul. Eng., ASCE, 128(9), 811-820 (2002)

8. C. Berger, B.W. McArdell, B. Fritschi, F. Schlunegger, A novel method for measuring the timing of bed erosion during debris flows and floods, Water Resour. Res., 46, W02502 (2010)

9. M. F. Mia, H. Nago, Design method of time-dependent local scour at circular bridge pier, J. Hydraul. Eng., ASCE, 129(6), 420-427 (2003)

10. J.-Y. Lu, Z.-Z. Shi, J.-H. Hong, J.-J. Lee, R.V. Raikar, Temporal variation of scour depth at nonuniform cylindrical piers, J. Hydraul. Eng., ASCE, 137(1), 45-56 (2011)

11. R. Diab, Experimental Investigation on scouring around piers of different shape and alignment in gravel, $\mathrm{PhD}$ thesis, Darmstadt (2011)

12. F. Ballio, A. Radice, A non-touch sensor for local scour measurements, J. Hydraul. Res., 41(1), 105-108 (2003)

13. O. Link, F. Pfleger, U. Zanke, Characteristics of developing scour-holes at a sandembedded cylinder, Int. J. Sediment Res., 23(3), 258-266 (2008)

14. F. Pfleger, C. Rapp, M. Manhart, Experimental investigation on the sediment movement in the vicinity of a cylindrical bridge pier, River Flow 2014, 1701-1708 (2014)

15. P.X. Ramos, A.M. Bento, R. Maia, J.P. Pêgo, Characterization of the scour cavity evolution around a complex bridge pier. Journal of Applied Water Engineering and Research, 4(2), 128-137 (2016)

16. E. Lachat, H. Macher, M.-A- Mittet, T. Landes, P. Grussenmeyer, First experiences with kinect V2 sensor for close range $3 D$ modelling. International Archives of the Photogrammetry, Remote Sensing and Spatial Information Sciences - ISPRS Archives, 40(5W4), 93-100 (2015)

17. S. Amaral, Experimental characterization of the failure by overtopping of embankment dams, $\mathrm{PhD}$ thesis, Instituto Superior Técnico, Lisbon, Portugal (2017)

18. S.O. Lee, T.W. Sturm, Effect of sediment size scaling on physical modelling of bridge pier scour. J. Hydraul. Eng., ASCE, 135 (10), 793-802 (2009)

19. Y.M. Chiew, B.W. Melville, Local scour around bridge piers, J. Hydraul. Res., ASCE, 25(1), 15-26 (1987)

20. C.R. Neil, Mean velocity criterion for scour of coarse uniform bed material. Proceedings of XII IAHR Congress, Fort Collins, Colorado, USA (1967) 